\title{
A EXPERIÊNCIA DE OCUPAR E AS PRÁTICAS FORMATIVAS: OCUPAÇÕES SECUNDARISTAS EM MINAS GERAIS EM 2016
}

\author{
LuIs AntÔNIO Groppo \\ Mara Aline Oliveira \\ Douglas Franco Bortone \\ Juliana Pereira \\ Priscilla Nayara de Morais \\ ANDREIA DA SILVA \\ Universidade Federal de Alfenas (UNIFAL), Alfenas, Minas Gerais, Brasil
}

\begin{abstract}
RESUMO: $\mathrm{O}$ artigo tem como objetivos conhecer a dinâmica das ocupações estudantis em Minas Gerais em 2016 e analisar as práticas formativas vividas pelas/os ocupas, com base em revisão bibliográfica e entrevistas semiestruturadas. Com base no legado da reflexão sobre o caráter educacional dos movimentos sociais, em cotejo com a noção de subjetivação política de Ranciére, concluímos que o movimento em Minas Gerais, em sua dinâmica política, marcou as/os ocupas de forma contraditória, mas destacando práticas formativas que renovam a tradição educacional dos movimentos sociais progressistas.
\end{abstract}

Palavras-Chave: Ocupações estudantis. Práticas formativas. Movimento social.

\section{INTRODUÇÃO'}

Este artigo analisa as ocupações de escolas por estudantes do Ensino Médio no segundo semestre de 2016, em Minas Gerais. Tem como objetivos conhecer a dinâmica dessas ocupações e analisar o que estas/es estudantes, que chamamos de ocupas, apontam como tendo sido os seus principais aprendizados com o engajamento na ação coletiva.

Desse modo, o artigo dialoga com a tradição teórica e pedagógica que valoriza a dimensão educacional dos movimentos sociais, como a que se apresenta na obra de Paulo Freire (1987) e Miguel Arroyo (2003). Essa tradição não apenas aponta as propostas de educação escolar que emanam dos movimentos sociais e dos seus sujeitos, mas, antes disso e até com mais destaque, valoriza os aprendizados e as práticas formativas intrínsecas às suas ações coletivas.

Teoricamente, o artigo também busca dialogar com a noção de subjetivação política de Jacques Rancière (1996). Trazemos a proposta de analisar a vivência da ocupação como um momento de subjetivação política: 


\begin{abstract}
Por subjetivação vamos entender a produção, por uma série de atos, de uma instância e de uma capacidade de enunciação que não eram identificáveis num campo de experiência dado, cuja identificação portanto caminha a par com a reconfiguração do campo da experiência (RANCIÉRE, 1996, p. 47).
\end{abstract}

Trazida para a pesquisa, consideramos que a ocupação desconstrói ou desloca os sentidos dados pela ordem social e pelos arranjos institucionais da condição adolescente e estudantil, abrindo espaços também para os mesmos efeitos em relação a gênero, raça e orientação sexual.

Trata-se de uma investigação qualitativa, atenta aos diversos cenários e às múltiplas experiências vividas no movimento, com base em revisão bibliográfica e, principalmente, em entrevistas semiestruturadas com estudantes que participaram de ocupações de escolas de ensino médio. Foram feitas 14 entrevistas em Minas Gerais, entre maio e agosto de 2019. Elas duraram entre 40 minutos e 2 horas, seguindo um roteiro com questões que abordavam a trajetória escolar, a formação política, a experiência de ocupar e a trajetória pós-ocupação. A maioria das pessoas entrevistadas, eram do Sul de Minas Gerais (sete de Poços de Caldas e três de um pequeno município), duas eram da capital, Belo Horizonte, região central do estado, e duas em Juiz de Fora, na Zona da Mata. ${ }^{2}$

Em nossa pesquisa bibliográfica, encontramos 12 trabalhos acadêmicos que tratam das ocupações estudantis de 2016 em Minas Gerais. Desses, 9 trabalhos foram criados por integrantes do Grupo de Estudos sobre a Juventude da UNIFAL-MG - o mesmo Grupo responsável pelo presente artigo -, que tratam de ocupações de instituições de educação básica e educação superior pública no Sul de Minas Gerais. Esses trabalhos fizeram uso de técnicas de coleta de dados que privilegiaram a observação e as entrevistas e o referencial teórico da sociologia da juventude e da subjetivação política. Outros trabalhos se aproximaram desta tendência metodológica e teórica, bem como tenderam a demonstrar a importância desse movimento na formação política das/os ocupas, promovendo mesmo uma repolitização das categorias juventude e estudante.

Este artigo se estrutura em três partes: uma síntese acerca da dinâmica das ocupações secundaristas em Minas Gerais em 2016; a análise das entrevistas com ocupas de Minas, destacando as experiências formativas vividas por tais estudantes, que chamamos de ocupas; e considerações conclusivas.

\title{
AS OCUPAÇÕES EM MINAS GERAIS, EM 2016
}

A pesquisa bibliográfica, ao lado de relatos colhidos nas entrevistas, ajuda a reconstruir em linhas gerais a história do movimento das ocupações nesse estado no $2^{\circ}$ semestre de 2016.

Já consolidado o impeachment de Dilma Rousseff, o governo Temer adotou políticas neoliberais em sentido estrito, a começar pela educação, com a Medida Provisória n. 746 (MP 746), que, transformada na Lei no 13.415/2017, reformou o Ensino Médio no país. A seguir, encaminhou o desmonte dos direitos sociais, com a Proposta de Emenda Constitucional n. 241 (PEC 241), depois PEC 55 e, enfim, a Emenda Constitucional 
95, que alterou o Regime Fiscal da União, congelando por 20 anos os gastos sociais. No início de outubro de 2016, começou uma onda nacional de ocupações de instituições de educação contra essas medidas, inicialmente no Paraná, logo atingindo Minas Gerais.

Segundo Gonçalves e Rena (2019), 157 escolas públicas de Educação Básica foram ocupadas em Minas Gerais entre outubro e dezembro de 2016, envolvendo 55 municípios. A primeira ocupação se deu na capital Belo Horizonte, em 6 de outubro, onde mais 23 escolas foram ocupadas. No entanto, Uberlândia foi o município mineiro com maior número de escolas ocupadas (25), indicativo do enraizamento e interiorização deste movimento.

Uberlândia também é exemplo da judicialização de ações coletivas, em geral de modo desfavorável às/aos ocupas: uma liminar da Vara da Infância e Adolescência ordenou a desocupação das escolas em 7 de novembro de 2016. O mesmo aconteceu no dia seguinte, em Poços de Caldas, no Sul de Minas, município que ficou na quarta posição no estado em número de escolas ocupadas, ao lado de Betim, na Região Metropolitana de Belo Horizonte, cada qual com 6 escolas. O terceiro posto coube a Unaí, no Noroeste do estado, com 9 escolas.

Em geral as ocupações duraram em torno de dois meses. A maioria das escolas foi sendo desocupada por iniciativa das/os ocupas, tanto pela aprovação da PEC 55 pelo Senado quanto pela grande redução do número de ocupas, com a aproximação das férias escolares. Betim teve, provavelmente, a ocupação mais longa e a última a se encerrar, já em 3 de fevereiro de 2017 (GONÇALVES; RENA, 2019).

Apesar da pauta ser nacional, a dinâmica das ocupações foi bastante influenciada pelo modo como os governos estaduais lidaram com o movimento, como já tinha acontecido com as ocupações anteriores, cujas pautas foram estaduais, entre novembro de 2015 e julho de 2016, respectivamente em São Paulo, Goiás, Mato Grosso, Rio de Janeiro, Rio Grande do Sul e Ceará.

No caso em questão, contou bastante a posição partidária do governo estadual em relação ao governo federal. Em Minas Gerais, o governo era do mesmo partido da presidente afastada, o Partido dos Trabalhadores (PT). Inicialmente, a Secretaria Estadual de Educação de Minas Gerais (SEE-MG) parece ter contribuído para o movimento e, durante toda a sua duração, se posicionou em favor do diálogo com as Superintendências Regionais de Ensino (SREs) e direções de escolas e em desfavor de pedidos de reintegração de posse. Contudo, a despeito da posição do SEE-MG, há diversos relatos acerca da pressão de algumas SREs, ao lado de direções, para o retorno das aulas "ao lado da ocupação", fazendo com que em algumas escolas convivessem com dois modos de gestão educacional e processos de ensino diferentes (COSTA; LOPES, 2018). As duas entrevistadas de escolas de regiões centrais da capital relataram que, desde o início, foram mantidas as aulas ao lado das ocupações, o que não evitou tensões e conflitos. A posição do SEE-MG também não evitou que fossem movidos processos judiciais que decidiram pela desocupação de escolas, ao menos em Uberlândia e Poços de Caldas.

Poços de Caldas é um exemplo da complexidade do movimento em Minas Gerais e do quanto ele afetou diversos sujeitos e organizações. O município teve a sua primeira escola ocupada em 18 de outubro de 2016. Ao final do mês, contabilizou a ocupação de mais cinco escolas estaduais e de uma escola municipal, além de uma universidade estadual e um instituto federal. O movimento de ocupação atingiu seu ápice ao estrategicamente arquitetar, em 1 de novembro de 2016, uma manifestação pública em 
que, surpreendentemente, estudantes de várias escolas aproveitariam para ocupar a sede da SRE. A ocupação da SRE durou até o dia 8 de novembro e, com isso, o movimento inseriu na pauta questões locais relativas à infraestrutura das escolas, merenda e currículo, além dos temas nacionais.

Os relatos apresentam a influência do exemplo de experiências precursoras, em especial as de São Paulo e do Paraná. Em Betim, relatou-se o uso da cartilha "Como ocupar um colégio" (GONÇALVES; RENA, 2019), cuja versão sintetizada, que cabia na tela de um celular, também foi consultada por estudantes do Sul de Minas, conforme entrevista. Mas a maioria das entrevistas que fizemos relatou outras formas de conhecimento sobre a tática da ocupação, por meio de militantes, relatos de ocupas de outras escolas em assembleias e visitas a outras ocupações. Nesse sentido, as primeiras escolas ocupadas em cada município tiveram papel formativo e político relevantes, como estímulo e exemplo às demais. Buscaram criar redes de apoio para troca de informações e alinhar ações, afora visitas para conhecer as escolas ocupadas, compartilhar alimentos doados e ofertar oficinas e palestras.

Em preparação à ocupação, estudantes favoráveis faziam reuniões para a discussão da pauta, pesquisas sobre o movimento, reuniões com direção da escola e assembleias estudantis de deliberação (GONÇALVES; RENA, 2019, SILVA et al., 2018). Tal qual em outros estados, há relatos que atestam que as ocupações foram precedidas por processos de mobilização apoiados por diversas organizações da esquerda. Temos isso nas entrevistas de Belo Horizonte, assim como em Uberlândia, conforme Morais, De Sordi e Fávero (2019), em que, em 5 de outubro de 2016, estudantes e militantes debateram em audiência pública na Câmara Municipal, a PEC 241/55, a MP 746 e a denominada "Escola sem partido" - ainda que as primeiras escolas tenham sido ocupadas em Uberlândia apenas em 18 de outubro.

A primeira ocupação no Sul de Minas também se deu em 18 de outubro de 2016, em Poços de Caldas. Diferentemente da maioria dos exemplos registrados, a primeira ocupação em Poços ocorreu na forma de um "trancaço" surpresa promovido por estudantes do Grêmio da escola e militantes que apoiaram a ação. A surpresa já criou grande tensão e ameaças de invasão por estudantes contrários, além do assédio de um policial militar que adentrou a escola e exigia sua desocupação.

As entrevistas, em especial no Sul de Minas, registraram a predominância de uma matriz discursiva, também observada em Betim, "majoritariamente autônoma e apartidária" (GONÇALVES; RENA, 2019, p. 225). Contudo, essa matriz foi, de diferentes formas, "perpassada por discursos provenientes de fora, principalmente dos movimentos sociais, movimento estudantil e juventudes partidárias situados ideologicamente à esquerda" (GONÇALVES; RENA, 2019, p. 226).

Em especial as escolas centrais e de bairros de classe média - mesmo em municípios interioranos de grande porte - contaram de modo relevante com a presença de militantes de organizações estudantis e partidárias de esquerda. Militantes, ao lado de docentes da escola, estudantes e docentes de universidades, advogadas e advogados de partidos e sindicatos entre outras/os, foram importantes, segundo várias entrevistas e pesquisa bibliográfica, na organização e preparação do movimento, em negociações com direções, SREs e autoridades e concedendo informações políticas e jurídicas. Nessas 
mesmas escolas, tenderam a ser mais profícuas as doações materiais - alimentos, colchões, cobertores etc.- e educacionais.

Esse apoio caía muito quando se tratava de escolas periféricas ou de municípios de menor porte. Segundo relato de ocupa de uma escola periférica do Sul de Minas, "teve dia em que não tínhamos nada pra comer, fazíamos pouca coisa e dividíamos" (Raven). Relato de ocupa de escola famosa na capital reitera esse dado, assim como registra o esforço de ocupas para criar uma rede de apoio que contemplasse as escolas não centrais, algo que também encontramos em Poços de Caldas:

\begin{abstract}
Todos os dias a gente tinha atividade para fazer na ocupação e, como é uma escola conhecida, a gente tinha fila de pessoas esperando para dar oficina, aula pra gente, ao contrário de muitas escolas de periferia [...], em que a galera tinha que se virar para arrumar oficina. [...] Também não faltou comida. Ai a gente era um ponto de distribuição, a gente pegava comida, aí a galera do "Ocupa Minas", que foi um movimento que rolou, distribuía nas escolas estaduais (Elionor).
\end{abstract}

Em muitas escolas os grêmios não existiam, eram inoperantes ou eram controlados pelas direções, em especial nas periféricas (MORAIS; DE SORDI; FÁVERO, 2019), de modo que a construção das ocupações e sua manutenção em diversos casos não partiu dos grêmios, não contou com seu apoio e até mesmo ocorreu a despeito da sua oposição. É importante também considerar relatos sobre pais, mães e docentes que pernoitaram ou ajudaram na limpeza e na cozinha, e assim, em diferentes graus, também foram ocupas.

O trabalho de Morais, De Sordi e Fávero (2019) sobre Uberlândia reafirma o que diversos outros trabalhos têm concluído a respeito da experiência formativa das ocupações: ocupas projetaram uma escola cuja perspectiva de ensino-aprendizagem se deixa representar pela figura do círculo e em que se estimula a curiosidade, a busca do conhecimento e o debate, cujo currículo passa a valorizar conteúdos subsumidos, como a arte e a formação política, e cuja gestão busca ser democrática e capaz de ouvir e considerar a posição de discentes.

O artigo de Costa e Lopes (2018) trata do currículo das ocupações, com temas como racismo, preconceito, gênero, machismo, feminismo, educação ambiental, conjuntura política, atividades lúdicas para corpo e mente, artes (música, pintura, teatro, dança), pilates e esportes. As entrevistas relatam também oficina de maracatu, capoeira, filtro de sonhos, brincos, câmeras, estêncil, desenho, contação de histórias, circo, slackline, karatê, horticultura e massagem. As atividades culturais foram consideradas tão importantes quanto as oficinas, como saraus, festivais, apresentações musicais, recitação de poesias, batuques, feira de ciências, recreação para crianças em escolas com Ensino Fundamental e ensaio de escola de samba.

Em um dos primeiros artigos sobre as ocupações em MG, o Grupo de Estudos sobre a Juventude da UNIFAL-MG considerou que o termo autogestão sintetizava muitas das características políticas e formativas do movimento: ilustrava uma inesperada defesa da escola, tendo em vista a produção acadêmica vigente sobre a relação (difícil) entre adolescentes e Ensino Médio; descrevia a capacidade de auto-organização do espaço escolar, das atividades formativas; e indicava a presença de princípios da democracia participativa e da horizontalidade. (GROPPO et al, 2017). 
Gonçalves e Rena (2019) falam claramente em lideranças, e de que elas eram em sua maioria do sexo feminino. Elas, porém, que tinham estimulado a ocupação, tinham um papel mais de referência do que de comando, já que tendiam a ser mais fortes a horizontalidade e as decisões tomadas em assembleia (GONÇALVES; RENA, 2019). Isso não impediu de verificarmos tensões e conflitos, como na escola sul-mineira, em que organização ligada à JPT (Juventude do PT), orientada por concepção vertical sobre a tomada de decisões, teria interrompido essa horizontalidade e a própria autonomia tão desejada pelas/os ocupas. Em algumas escolas, como entrevista de ocupa de Belo Horizonte revela, a autonomia das/os ocupas teve de ser garantida em meio às disputas entre militantes de entidades estudantis de esquerda rivais.

Um dos elementos políticos e pedagógicos mais potentes das ocupações em MG, assim como em todo o país, foi o feminismo (SILVEIRA, 2019). Configura-se um novo feminismo no Brasil, em marcha ascendente ao menos desde as Jornadas de 2013, marcadamente juvenil e, a partir das primeiras ocupações, em São Paulo em 2015, também adolescente e periférico. Um dos relatos é patente neste aspecto: “Não tem como não se sentir mais forte como mulher depois das ocupações. Deu-me coragem para debater várias coisas que eu não tinha coragem, em casa, na família, nos relacionamentos, na universidade, na escola e em qualquer lugar" (Joana apud SILVEIRA; GROPPO, 2019, p. 34).

Os principais algozes da/os ocupas, que diversas vezes atentaram contra seus direitos civis e políticos, foram sujeitos que também lideraram a repressão nos demais estados: burocracias escolares e polícias militares (MEDEIROS; JANUÁRIO; MELO, 2019). Ainda entre os adversários estiveram parte da sociedade civil e das imprensas locais, que em alguns casos ajudaram a organizar ações violentas e ilegais de desocupação de escolas. Em todos os estados, até agora, quase todas as entrevistas de ocupas trazem registros de medo, repressão, violência, angústia e desgaste mental e físico. No entanto, no caso de Minas Gerais, os registros têm sido os mais marcantes e abundantes, diante da longa duração do movimento nesse estado e diante das ameaças e das represálias de vários sujeitos adultos, incluindo parte da burocracia escolar. Um exemplo é este relato de ocupa da primeira escola do Sul de Minas:

Desde o primeiro dia, eu e a Maria, a gente só chorava. [...] Era o tempo todo chorando de medo, porque era o tempo todo muita ameaça. A Maria, depois de um tempo da ocupação, ela não andava sozinha, e eu andava sozinha, mas sempre com um pé atrás [...]. A gente tentou colocar aula letiva para os alunos lá dentro, aulas de professores voluntários. Mesmo com os alunos recebendo presença, tocaram uma bomba de fumaça lá dentro que assustou todo mundo e os alunos saíram correndo. (Carolina de Jesus, entrevista, Poços de Caldas).

Em Betim, assim como no Sul de Minas, foram atiradas pedras e bombas em algumas escolas, faixas e cartazes foram arrancados, houve pichações e textos ofensivos nos muros, tentativas de arrombamento, invasão e agressão (GONÇALVES; RENA, 2019). Em Poços de Caldas, algumas escolas foram invadidas por policiais fortemente armados 
GROPPO, L. A.; OLIVEIRA, M. A.; BORTONE, D. F.; PEREIRA, J.; MORAIS, P. N. de SILVA, A. da

para cumprir mandado judicial de desocupação, mesmo onde ocupas já estavam organizando a devolução da escola:

Vieram policiais com metralhadoras [...] dentro da escola com crianças de 13 anos de idade [...], transitando, empurrando os alunos para fora, interrompendo a aula que já havia retornado. [...] Nesse momento eu senti muito medo, os professores choraram [...], mas nossa direção aplaudiu (Have, Poços).

Have ainda traz um exemplo de relatos que tratam de represálias e perseguições após o fim das ocupações: "Tinha um policial dentro da escola, que falou: 'você não vai entrar aqui até semana que vem"'.

\section{GANHOS, FRUSTRAÇÕES E APRENDIZADOS NA EXPERIÊNCIA DE OCUPAR}

Entre as 14 pessoas entrevistadas, apenas duas negaram que a ocupação tenha sido uma experiência de grande e positiva influência em suas trajetórias pessoais: Sandro e Gabriela. Sandro (Juiz de Fora) considerou o episódio como tendo pouca importância para sua formação política. Ele era o mais velho das pessoas entrevistadas (tinha 23 anos) e já relativamente experimentado na militância de uma juventude partidária, a União da Juventude Socialista (UJS), que valoriza a organização em detrimento da ação direta e independente. Já Gabriela (Sul de MG), que se desgostou com a interferência da JPT na ocupação de sua escola, considerou a experiência apenas como negativa para sua trajetória. Entretanto, o caso de Gabriela é pelo menos ambíguo. Ao final da entrevista, recordou da empolgação no início da ação e reconheceu que a experiência influenciou sua decisão de ser professora.

As outras 12 pessoas consideraram que a experiência de ocupar teve grande importância para elas. Mesmo duas militantes da UJS durante a ação coletiva, Bianca (Juiz de Fora) e Elionor (Belo Horizonte), reconheceram isso. Para duas pessoas, ocupar parece ter sido a principal experiência de suas vidas: "Melhor experiência da minha vida, tudo que passei lá dentro me fez ver o Raven como pessoa" (Raven, Sul de Minas Gerais); "Foi a época em que eu me senti mais viva" (Nakas, Poços de Caldas).

Duas questões feitas nas entrevistas ajudaram a compreender melhor o alcance e os sentidos dessa experiência. Uma delas pergunta o que foi mais gratificante na ocupação, e a outra, o que foi mais frustrante.

Para analisar as respostas sobre o que foi mais gratificante, elaboramos dois núcleos de significação: o primeiro, centrado nas características ou efeitos políticos do movimento; o segundo, centrado na importância pessoal ou impacto subjetivo. No primeiro núcleo, com 8 menções, temos: atividades formativas (3 ocupas), repercussão nacional do movimento (2), união das/os ocupas (1), organização estudantil (1) e reconhecimento das/os estudantes para as decisões relativas às políticas educacionais (1). No segundo núcleo, com 11 menções, temos: mais conhecimento de si/forte mudança pessoal (4), amizades (3), reconhecimento (2), pertencimento à escola (1) e decisão de ser professora (1).

As respostas destacam os aspectos pessoais e subjetivos, pois a própria questão remetia ao impacto individual. As características do movimento, ainda assim, ganharam 
grande importância, apesar de que 3 das 8 menções tenham vindo do militante Sandro, duas delas destacando a relação com as organizações políticas (organização e decisões políticas). Chama muito a atenção o que a ocupação significou para 4 pessoas: acima de tudo, uma importante mudança pessoal, o que indica a permanência de uma marca poderosa na memória e na consciência delas, provinda da participação em uma ação coletiva quando adolescentes. Também chama muito a atenção a importância de aspectos educacionais, não apenas pela menção ao pertencimento à escola e à decisão de ser professora, mas pelas 3 menções, no primeiro núcleo de significação, às atividades formativas durante a ocupação. Isso reforça a importância da experiência da ocupação em aspectos formativos e novas concepções sobre a educação e a escola, que reencontraremos adiante, nas narrações sobre o que foi mais marcante durante o movimento.

As respostas em relação ao que foi mais frustrante têm menos diversidade. No que elas têm de mais frequência, repetem o que já descrevemos no item anterior, sobre a dinâmica das ocupações: 5 respostas trataram da derrota do movimento em relação à pauta de derrubada da PEC 241/55 e MP 746; 4 respostas trataram das ameaças, agressões e perseguições durante e após a ocupação. Uma resposta se queixou do risco de militantes apoiadores tomarem para si a escrita da história do movimento. Outra se queixou do baixo número de estudantes que participaram das oficinas e atividades formativas oferecidas - queixa que apareceu, em outros momentos, em mais algumas entrevistas. Essa resposta demonstra que as ocupações foram movidas por um baixo número de pessoas, que tendeu a diminuir com o passar do tempo, principalmente em longos processos como se observou nesse estado. Ou seja, a proporção de estudantes que se tornaram ocupas era bem pequeno em relação ao número total de discentes da escola. Mesmo atividades com a intenção de envolver mais estudantes e a sociedade local, muitas vezes se viram frustradas. Isso deve nos alertar para não idealizarmos o movimento das ocupações, nem desconsiderar os seus limites.

Relatos sobre as vivências mais marcantes durante a ocupação também foram selecionados nas entrevistas. Consideramos que elas podem ser traduzidas, principalmente, na forma de aprendizados. Desse modo, encontramos os seguintes aprendizados, ordenados pela frequência com que foram citados:

a) Concepção de educação. As principais referências foram as diferentes formas de ensino-aprendizagem e os conteúdos alternativos ensinados durante a ocupação. Duas ocupas destacaram inclusive aprender a cozinhar e lavar banheiro, bem como saber a importância dessas tarefas e de quem as cumpre cotidianamente. Também citam algumas mudanças na escola após a ocupação, que se tornou mais democrática ou adotou algumas vivências educacionais alternativas (como as carteiras em círculo) e, enfim, a valorização da/o docente.

A gente estava tendo outras aulas que a gente nunca ia poder ter. [...] nesse momento, a gente teve aula de ioga pra gente relaxar. A gente teve aulão sobre ENEM, de física, matérias que sabe que pega um pouco, [...] teatro, dança (Pagu, Poços de Caldas).

Foi gratificante ver a escola com outra cara. [...] Chegar lá e ver um céu bonito e as pessoas fazendo várias coisas diferentes, tendo aula, 
GROPPO, L. A.; OLIVEIRA, M. A.; BORTONE, D. F.; PEREIRA, J.; MORAIS, P. N. de SILVA, A. da

só que com muita árvore. Ver as aulas de biologia sendo ali. E vendo a galera cozinhando, aprendendo a cozinhar, ver a galera aprendendo a limpar um banheiro, ver a galera aprendo a andar de slackline. Ver a galera aprendendo coisas diferentes (Elionor, Belo Horizonte).

As aulas, a gente pediu para eles montarem diferente [...] e não fazer aquela aula muito normal, um sentado atrás do outro. Pedimos para o professor se sentar junto com o aluno. [...] Todo mundo sentado, conversando, olhando um para o outro, eu acho muito melhor (Carolina de Jesus, Poços).

Acho que o que a gente mais aprendeu na ocupação é que a gente vivia um modelo de escola que não era o modelo que a gente se encaixava. Que é um modelo que estava fadado a projetos que queriam destruir a educação. Então, tem escolas em que hoje, depois da ocupação, os estudantes não sentam mais em fileiras, os estudantes sentam em círculos. Tem escolas que aos sábados e aos domingos abrem para as famílias. Tudo isso por causa do período de ocupação (Bianca, Juiz de Fora).

b) Influência na decisão de cursar a Educação Superior (ES) e no tipo de carreira. Onze (11) ocupas, inclusive 2 que ainda não haviam ingressado na ES, reconheceram essa influência. Durante as entrevistas, 10 ocupas estavam na ES e uma havia evadido por causa do trabalho. Seis (6) estudavam em Instituições de Educação Superior (IES) públicas. O contato com militantes que eram estudantes da ES favoreceu muito o conhecimento dos processos de seleção e as possibilidades de cursar IES públicas e privadas. Alguns relatos falam da influência em procurar dada carreira pelo reconhecimento da dimensão social e política das profissões com a experiência da ocupação, outros do contato com profissionais de Psicologia que ministraram oficinas nas escolas.

Nós tivemos aulão. Teve oficina, teve palestra. E entre a gente conversamos muito sobre nossos direitos. Era um tipo de despertar. [...] Eu tive muita facilidade de entrar na universidade pública, porque eu já conhecia o espaço., eu tive facilidade de entender o ambiente acadêmico (Cássia Eller, Belo Horizonte).

Raven (Sul de Minas Gerais), durante assembleia com estudantes, docentes e responsáveis no início da ocupação, após uma discussão, foi agredido pela vice-diretora com um tapa nas costas: "Eu falei para ela que um dia iria me formar e ser professor, e nunca iria fazer o que ela fez. Ela sorriu, dizendo que nunca iriamos conseguir". Tempos depois, a reencontrou em evento na universidade onde ele cursa Pedagogia:

Ela me viu e ficou surpresa em me ver dentro da universidade. Foi uma das coisas mais prazerosas que já senti. Pensando bem, não me imaginava em uma universidade, porque venho de uma família desestruturada, moro num bairro distante, não tenho condições financeiras. Eu lutei pra estar ali. Lembrei de tudo na hora que vi a cara dela. Eu acho que foi muito marcante e superei essa situação (Raven, Sul de Minas Gerais). 
c) Capacidade de crítica e autocrítica. Vários relatos trataram da abertura de si ao mundo, da quebra de preconceitos e desenvolvimento do pensamento crítico.

As ocupações me tornaram uma pessoa melhor, porque eu soube como funciona, por exemplo, a atividade em grupo [...], como funcionava algumas coisas dentro da política, foi lá que eu comecei a pensar nas coisas, não só sobre o que se passava comigo (Pagu, Poços de Caldas).

A minha cabeça era muito pequena, e a ocupação me ajudou a abrir minha cabeça, me ajudou a expandir meus horizontes. (Johnny Cash, Poços de Caldas).

Foi uma formação política muito grande que a gente teve que ter, que eu acho que a gente não teria em outra oportunidade, ter um raciocínio mais crítico daquilo, de tentar pesquisar melhor - porque antes a gente [...] acreditava muito naquilo que estava na nossa frente, que estava fácil de a gente consumir. [...] A gente não está vendo só o nosso lado, a gente não vê só o eu, Humberto, a gente vê toda uma sociedade, todas as pessoas, tudo que essas pessoas vão sofrer [...] com o que alguma coisa de mal possa trazer pra sociedade (Humberto, Sul de Minas Gerais).

d) Esforço para dialogar com outros sujeitos, como estudantes que não eram ocupas, docentes e comunidade. Os relatos tratam de assembleias, aulões, oficinas abertas e divulgação de atividades pelas redes sociais, buscando esclarecer os motivos da ocupação e demonstrar que estavam ocorrendo ações educacionais na escola ocupada mesmo quando não houve eficácia.

Tinha dois dias na semana que íamos em todos os bairros, entregávamos os panfletinhos e pedíamos alimentos. Então, começaram a enxergar porque a gente estava lutando e que a gente não estava ali à toa (Raven, Sul de Minas Gerais).

A gente fez horta comunitária, a gente fez brincadeiras, chamamos pais para reunião e teve muita bobagem na reunião, passamos muito nervoso. Mas eu acho que valeu a pena no final, pela aprendizagem que a gente levou, em questão de abrir os horizontes e enxergar realmente o mundo como ele é (Kahlo, Poços de Caldas).

e) Descoberta ou clareza sobre a orientação sexual não heteronormativa. Quatro (4) ocupas citaram que a participação no movimento foi importante para definirem sua orientação como não heteronormativa: Elionor como pansexual, Kahlo como lésbica, Johnny Cash como "sem definição" e Raven compreendendo melhor sua homossexualidade.

Eu sempre tive dúvida da minha sexualidade, e a ocupação me ajudou a descobrir (Johnny Cash, Poços de Caldas).

A primeira vez que eu me apaixonei por uma menina foi numa ocupação (Elionor, Belo Horizonte). 
GROPPO, L. A.; OLIVEIRA, M. A.; BORTONE, D. F.; PEREIRA, J.; MORAIS, P. N. de ; SILVA, A. da

f) Solidariedade e coletivismo. Relatos se referem à descoberta da importância do trabalho coletivo, do apoio mútuo e da capacidade de gerir, de modo solidário, a ocupação.

Foi gratificante a união de todos os alunos que estavam ali, lutando pra um mesmo propósito. [...] Se caísse pra um lado, um segurava, e se outro caísse pra esse outro lado, outro segurava (Humberto, Sul de Minas Gerais).

Eu acho que é importante a gente sempre ter alguém pra lugar com a gente. [...] Porque se eu estivesse sozinha, eu não ia conseguir. [...] Eu trouxe isso pra vida pessoal também (Beatriz, Poços de Caldas).

g) Perceber-se como parte de um movimento maior, em âmbito nacional.

Foi gratificante ver do que a gente fez parte, de quantas outras escolas foram ocupadas com a gente incentivando [...] a lutar por aquilo, a pensar naquilo, de ver a importância e ficarem revoltados. [...] Todo mundo, pelo menos, ficou ciente do que estava acontecendo. A gente fez todo mundo pensar, pelo menos parar para ver se a gente estava aqui. [...] a gente fez parte de um movimento muito grande (Carolina de Jesus, Poços de Caldas).

Com a recolha e a análise destes relatos, este trabalho busca se engajar na tradição teórica e pedagógica que valoriza a dimensão educacional dos movimentos sociais e a educação popular. Como dito, essa tradição sistematiza propostas educacionais que emanam dos movimentos sociais e que influenciam o ensino e a escola. Mas ela também valoriza os aprendizados e as práticas formativas intrínsecas às ações coletivas. $\mathrm{Na}$ tradição da educação popular, as experiências vividas pelas classes populares são o ponto de partida e um dos fundamentos dos processos educacionais que se deseja propor a esses sujeitos (FREIRE, 1987). Entre essas experiências, a luta pela sobrevivência, o trabalho, as agruras da exploração e os próprios movimentos sociais.

\begin{abstract}
A Pedagogia do oprimidoé essencialmente uma pedagogia daquele outro que se encontra na margem. Por isso, parece tão pouco pertinente perguntar se a pedagogia de Paulo Freire ainda tem validade ou se ela pode ser aplicada, por exemplo, em escolas da rede pública, em universidades ou em projetos de educação de jovens e adultos. $\mathrm{O}$ equívoco consiste em se perder de vista que se trata de perceber o movimento pedagógico recriado nesses espaços marginalizados da sociedade (STRECK, 2009, p. 175).
\end{abstract}

Arroyo (2003) vai ainda além e busca delinear as características educacionais que têm emanado dos movimentos sociais progressistas no Brasil: a luta pelo direito à educação e, durante a luta, o aprendizado dos direitos como cidadã e cidadão; a valorização da luta pela sobrevivência e pela vida digna (a materialidade); a centralidade dos sujeitos na educação; o alargamento do olhar do sujeito acerca do mundo (totalidade); e a centralidade do tempo presente e da resolução de seus problemas (presentificação).

Os relatos têm indicado que as ocupações apresentam algumas destas características educacionais descritas por Arroyo (2003). As ocupações se trataram de um 
movimento cuja pauta central foi a educação e o direito à educação. Nele, ocupas aprenderam pela organização da luta, tanto quanto pelas oficinas e palestras no calor do movimento, sobre seus direitos como cidadãs e cidadãos - mais do que por meio de uma habilitação prévia via educação formal. A materialidade apareceu principalmente na forma do auto reconhecimento como estudante de escolas públicas, que vinham sofrendo com a precariedade da estrutura e do ensino e, agora, com as ameaças de ainda mais precarização. Mas a materialidade também aparece na forma da assunção a um feminismo secundarista e da clareza sobre a orientação sexual. A presentificação não está apenas na pauta, que era uma reação imediata contra medidas do governo federal, mas também no que tem sido chamado de pré-figuração: a vivência de uma heterotopia no âmbito da própria ação coletiva. (SANTOS, 2019). Enfim, os relatos indicaram forte presença da totalidade, como abertura de si para o mundo, e a centralidade dos sujeitos nos processos educacionais - era a partir delas e deles, tanto de quem ensina-e-aprendia, tanto de quem aprendia-e-ensinava, que emanavam os conteúdos, as metodologias e os objetivos das práticas formativas.

Esse último aspecto nos leva também ao diálogo com as categorias de educação não formal e educação informal (PARK; FERNANDES; CARNICEL, 2007). A educação não formal é aqui considerada como práticas educacionais planejadas, mas sem a formalidade do ensino ou da educação escolar, e centradas nos interesses dos próprios sujeitos aprendentes. A educação informal é considerada como práticas que, apesar de seu teor educacional, não foram planejados com esse fim, ou seja, são práticas sociais que têm caráter formativo incidental (não necessariamente inconsciente).

Nas ocupações, a educação não formal apareceu em oficinas e práticas assemelhadas, como rodas de conversa, debates e cine-debates, formato que reduzia a distância entre ministrantes e educandas/os, assim como reduzia a distância entre o saber e o fazer. Ela também apareceu na forma de "aulões", termo que, a princípio, remete à clássica aula, tanto na prática da exposição quanto nos conteúdos do currículo escolar. Mas o aumentativo demonstra sua aproximação ao formato das assembleias, pela presença esperada de uma "massa" de ouvintes, assim como a livre adesão, a horizontalidade e a participação. Enfim, aparentemente ainda mais próximo da educação formal, palestras com orientações de profissionais do Direito e militantes de idade adulta, mas que tinham finalidades bastante pragmáticas: informações sobre como evitar o confronto com forças policiais e autoridades, assim como construir uma imagem positiva da ação coletiva na comunidade e dialogar com a gestão e o governo.

Já a educação informal apareceu sobretudo na participação em reuniões e assembleias, elas próprias por vezes indiferenciadas de oficinas e "aulões", mas também na presença em manifestações e na própria organização do dia-a-dia da ocupação. Raven (Sul de Minas Gerais) relatou sobre o quanto foi importante para sua abertura ao mundo e conhecimento da relevância da política, a sua ida a Brasília para manifestação contra a PEC 55. Já Nakas (Poços de Caldas) considerou "divertido" limpar a escola, quando, ao mesmo tempo em que passaram a compreender as agruras do trabalho braçal das faxineiras, buscaram recriar o labor na forma de "uma bagunça organizada", promovendo uma guerrinha de água enquanto lavavam os banheiros. 
Essa coabitação entre práticas políticas e práticas educacionais informais e não formais faz com que as ocupações estudantis pareçam possuir algumas das características do que Boaventura de Sousa Santos (2019) chama de zonas libertadas. Das características citadas abaixo, estiveram presentes nas ocupações estudantis, principalmente, a autoeducação e a já comentada pré-figuração:

As zonas libertadas são comunidades consensuais baseadas na participação de todos os seus membros. Possuem uma natureza performativa, prefigurativa e educativa. [...] Podem surgir no contexto de processos de luta mais amplos ou ser resultados de iniciativas isoladas [...] podem ser vividas ou segundo uma lógica de confrontação ou segundo uma lógica de existência paralela. Vistas de fora, as zonas libertadas parecem juntar experiência social e experimentação social. Daí a dimensão educativa que as caracteriza: concebem-se a si mesmas como processos de autoeducação (SANTOS, 2019, p. 57, gritos do original).

As entrevistas parecem dar razão a essa caracterização das ocupações como zonas libertadas - ainda que tênues e provisórias - que se viam como comunidades de autoeducação. A transmissão da tática da ocupação entre ocupações, por meio de ocupas em grande trânsito e profícuo diálogo com outras escolas do município e até de outros estados, é um grande exemplo da dimensão auto educacional desse movimento. Também o fato de que as vivências mais marcantes relatadas por ocupas, como visto, deram grande destaque à educação em seu sentido amplo: coparticipação na criação de práticas formativas alternativas, ou a própria vivência delas, inclusive aprender a cuidar da escola, cozinhar e lavar banheiro; valorização da escola e da docência e de docentes; e percepção de algumas mudanças na escola. Mas os aspectos educacionais mais valorizados foram mesmo as práticas formativas da ocupação, tanto por seus conteúdos quanto suas metodologias e formas de gestão coletiva.

Esboçou-se uma pedagogia das ocupações, em que a participação no ato coletivo por si só suscitou emoções, sentimentos e vivências que foram consideradas como causadoras de uma transformação de si ou de sua própria evolução pessoal - a autoeducação de que fala Santos (2019), ou a totalidade segundo Arroyo (2003). Por exemplo, para quatro ocupas isso significou valorizar a prática da arte como uma forma de sensibilização e aprendizado, inclusive político. Também para quatro ocupas a vivência da ocupação permitiu descobrir ou assumir com mais clareza uma dada orientação sexual não heteronormativa.

A pedagogia das ocupações, em certo sentido, se aproxima do que Henry Giroux (2019) chama de pedagogia crítica, ou melhor, dos objetivos da pedagogia crítica: a responsabilidade com o coletivo, o envolvimento com o mundo de forma crítica, a participação democrática na própria escola e na sociedade, e o rechaço ao exercício abusivo do poder e da autoridade (inclusive, dentro do próprio movimento). Veja-se que esses objetivos aparecem em larga medida entre as principais vivências das/os ocupas de Minas Gerais. Como diferenças, a pedagogia das ocupações se deu principalmente por meio de práticas educacionais não formalizadas ou mesmo informais, mais do que uma orientação para a reconstrução do currículo escolar e o processo de ensino. Essas práticas foram combinadas ou inventadas nas escolas ocupadas via improviso, mas também pelo acúmulo de experiências de ocupas e apoiadores. 
Se o destaque das entrevistas foram os aprendizados e práticas formativas construídas com outras/os ocupas, também apareceu de modo importante o reconhecimento da contribuição de militantes mais experientes, de profissionais do Direito e até mesmo de docentes. A pedagogia das ocupações é, nesse sentido, uma bricolagem de diversas práticas formativas heterodoxas. O exemplo da figura do círculo, aquela figura que permite "olhar para o outro, conversar de frente" (Carolina de Jesus, Poços), tão caro às oficinas e reuniões, é relevante. Lá nos anos 1960, Paulo Freire (1985) já propunha os círculos de cultura, os quais materializariam a capacidade de todas as pessoas ensinarem e aprenderem, tanto quanto a possibilidade (e a necessidade) de que todas as experiências humanas se convertessem em saberes relevantes.

\section{CONSIDERAÇÕES FINAIS}

Este artigo tinha dois objetivos: conhecer a dinâmica das ocupações estudantis em Minas Gerais, no segundo semestre de 2016, no contexto do movimento nacional de ocupações, e analisar as práticas formativas vividas pelas/os ocupas. Buscamos atender esses objetivos a partir de revisão bibliográfica a respeito das ocupações mineiras e entrevistas semiestruturadas com 14 ocupas de três regiões desse estado.

A revisão bibliográfica, ao lado das entrevistas realizadas, foi relevante para fazer uma interpretação histórica, social e política das ocupações em Minas Gerais em 2016. Demonstrou-se como ocupas do estado se engajaram em uma mobilização de cunho nacional contra políticas regressivas do governo Temer, recém-empossado após um processo de impeachment que parece ter inaugurado uma escalada de desmonte, não apenas das políticas sociais mas do próprio Estado democrático no Brasil. Em Minas Gerais, as ocupações adotaram a pauta nacional, ainda que em alguns locais tenham inserido pautas locais, que levaram até mesmo à ocupação da sede da SRE em Poços de Caldas. A situação política em relação ao governo estadual do PT pareceu aí mais contraditória, enquanto que no Paraná, por exemplo, o governo estadual era mais bem alinhado à pauta neoliberal. Mas as ameaças e agressões vindas das forças policiais, da burocracia escolar e da própria sociedade foram muito evidentes, rasgando de alto a baixo os relatos da maioria das entrevistas. A experiência de ocupar significou a vivência de uma intensa formação política e aprendizados sobre artes, raça, diversidade sexual, gênero, feminismo, entre outros temas, mas também significou dores, angústias e traumas.

As entrevistas revelaram, enfim, o esboço de uma pedagogia das ocupações. Essa pedagogia se compôs de um arranjo improvisado de saberes e práticas heterodoxas, rebeldes e radicais, de fontes e tempos diversos. Em cotejo com a literatura sobre educação e movimentos sociais, as ocupações foram um exemplo de valores como a defesa da educação, o exercício da cidadania, a centralidade dos sujeitos na educação, a materialidade, a totalidade e a presentificação, conforme Miguel Arroyo. Em cotejo com a noção de educação não formal por Margareth Park, Renata Sieiro Fernandes e Amarildo Carnicel, temos que as oficinas e até mesmo os "aulões" e as palestras se baseavam em uma espécie de autodesenvolvimento de práticas formativas de livre adesão, voltadas aos interesses e necessidades da/os aprendentes, com metodologias que valorizavam a 
GROPPO, L. A.; OLIVEIRA, M. A.; BORTONE, D. F.; PEREIRA, J.; MORAIS, P. N. de SILVA, A. da

participação e a gestão coletiva. Assim, fomos levados a pensar as ocupações tal qual as zonas libertadas de que trata Boaventura de Sousa Santos, em que experiência social e experimentação social são ao mesmo tempo processos individuais e coletivos de autoeducação.

Artigo recebido em: 02/06/2020

Aprovado para publicação em: 11/11/2020

THE EXPERIENCE OF OCCUPANCY AND FORMATIVE PRACTICES: SECONDARY OCCUPATIONS IN MINAS GERAIS IN 2016

ABSTRACT: The article aims to understand the dynamics of student occupations in Minas Gerais (MG) in 2016 and to analyze the formative practices experienced by the occupiers, based on bibliographic review and semi-structured interviews. Based on the legacy of the reflection on the educational character of social movements, in comparison with Ranciére's notion of political subjectivation, we conclude that movement in $\mathrm{MG}$, in its political dynamics, marked the occupiers in a contradictory way, but highlighting training practices that renew the educational tradition of progressive social movements.

KEYWORDS: Student occupations. Formative practices. Social movement.

\section{LA EXPERIENCIA DE OCUPAR Y LAS PRATICAS FORMATIVAS: OCUPACIONES SECUNDARIAS EN MINAS GERAIS EN 2016}

RESUMEN: El artículo tiene como objetivo comprender la dinámica de las ocupaciones de los estudiantes en Minas Gerais (MG) en 2016 y analizar las prácticas formativas experimentadas por los ocupantes, en base a una revisión bibliográfica y entrevistas semiestructuradas. Con base en el legado de la reflexión sobre el carácter educativo de los movimientos sociales, en comparación con la noción de subjetivación política de Ranciére, concluimos que el movimiento en MG, en su dinámica política, marcó los ocupantes de manera contradictoria, pero destacando las prácticas formativas. que renuevan la tradición educativa de los movimientos sociales progresistas.

PALABRAS CLAVE: Ocupaciones estudiantiles. Prácticas formativas. Movimiento social.

\section{NOTAS}

1) Este artigo sistematiza e discute resultados da pesquisa "Ocupações secundaristas no Brasil em 2015 e 2016: Formação e auto-formação das/dos ocupas como sujeitos políticos" (coordenada por Luís A. Groppo e financiada pelo CNPq com Bolsa de Produtividade em Pesquisa e por Chamada Universal) e da pesquisa "Ocupações secundaristas no Sul de Minas e o conceito de educação menor" (Pesquisa de Mara Aline Oliveira para a dissertação de mestrado em Educação da UNIFAL$M G)$. 
2) Conforme registro no Comitê de Ética de Pesquisa, as pessoas entrevistadas escolheram pseudônimos. Os nomes das escolas não serão citados, bem como os nomes dos municípios de pequeno porte.

\section{REFERÊNCIAS}

ARROYO, M. Pedagogias em movimento: O que temos a aprender dos Movimentos Sociais? Currículo sem Fronteiras. V. 3, n. 1, p. 28-49, 2003.

COSTA, M.; LOPES, G. B. Ocupo, logo resisto: 50 dias de ocupação em uma escola de Alfenas-MG. Três Pontos. Belo Horizonte, ano 15, n. 1, 2018, '; 56-66.

FREIRE, P. Educação com prática da liberdade, 16a ed. Rio de Janeiro: Paz e Terra, 1985.

FREIRE, P. Pedagogia do oprimido. 17a ed. Rio de Janeiro: Paz e Terra, 1987.

GIROUX, H. If classrooms are "Free of Politics", the righ twing will grow, Truthout. 13 maio 2019. Disponível em: < https://truthout.org/articles/if-classrooms-are-free-ofpolitics-the-right-wing-will-grow/>, acesso em 20 dez. 2019.

GONÇALVES, C. P. B.; RENA, L. C. C. B. O movimento de ocupação das escolas em Minas Gerais: formação política através da ação coletiva. In: MEDEIROS. J.; JANUÁRIO, A; MELO, R. (orgs.). Ocupar e resistir. Movimento de ocupações de escolas pelo Brasil (20152016). São Paulo: Editora 34, cap. 9, 2019, p. 222-243.

GROPPO, Luís Antonio et al. Ocupações no Sul de Minas: autogestão, formação política e diálogo intergeracional. ETD - Educação Temática Digital. Campinas, v.19 n.1 p. 141-164, 2017.

MORAIS, S. P.; DE SORDI, D. N.; FAVERO, D. G. F. Ocupação e contra ocupação de escolas públicas: o caráter político-educativo da mobilização coletiva. Trabalho Necessário. v.17, no 33, p. 138-161, 2019.

PARK, M. B.; FERNANDES, R. S.; CARNICEL, A. (org.). Palavras-chave em educação nãoformal. Holambra: Setembro; Campinas: CMU, 2007.

RANCIÈRE, J. O desentendimento: política e filosofia. São Paulo: Editora 34, 1996.

SANTOS, B. S. O fim do império cognitivo. A afirmação das epistemologias do Sul. Belo Horizonte: Autêntica Editora, 2019. 
GROPPO, L. A.; OLIVEIRA, M. A.; BORTONE, D. F.; PEREIRA, J.; MORAIS, P. N. de SILVA, A. da

SILVA, B. H. et al. (Re)conto das experiências sobre as ocupações de duas escolas em um município do sul de Minas Gerais. Revista Três Pontos. Belo Horizonte, ano 15, n. 2, 2018, p. 72-78.

SILVEIRA, I. "Lute como uma menina": gênero e processos de formação na experiência das ocupações secundaristas. Dissertação (Mestrado em Educação), Universidade Federal de Alfenas, Alfenas/MG, 2019, $103 \mathrm{f}$.

SILVEIRA, Isabella; GROPPO, Luís A. As ocupas e as ocupações secundaristas: feminismo, política e interseccionalidade. Revista Educação e Linguagens, Campo Mourão, v. 8, n. 14, p. 24-48, 2019.

STRECK, D. R. Uma pedagogia do movimento: os movimentos sociais na obra de Paulo Freire. Revista de Educação Pública. Cuiabá v. 18 n. 36 p. 165-177, 2009.

LuIs ANTÔNIO GROPPO: Pesquisador do CNPq, possui graduação em Ciências Sociais pela Universidade de São Paulo (1992), mestrado em Sociologia pela Universidade Estadual de Campinas (1996) e doutorado em Ciências Sociais pela Universidade Estadual de Campinas (2000). Desde 2013, é professor do curso de Ciências Sociais da Universidade Federal de Alfenas/MG (Unifal). Foi docente do Programa de Mestrado em Educação do Centro Universitário Salesiano de São Paulo (Unisal), entre 1998 e 2013. Tem experiência na área de Sociologia, com ênfase em Sociologia da Educação e Sociologia da Juventude, assim como na área de História dos movimentos estudantis.

Orcid: https://orcid.org/0000-0002-0143-5167

E-mail: luis.sroppo@smail.com

Mara Aline Oliveira: Graduada em Direito pela Pontifícia Universidade Católica de Minas Gerais (2012). Especialista em Filosofia pela Pontifícia Universidade Católica de Minas Gerais (2017). Atualmente é advogada responsável pelo departamento jurídico da região Sul de Minas Gerais do Sindicato Único dos Trabalhadores em Educação de Minas Gerais. Mestranda em Educação pela Universidade Federal de Alfenas (UNIFAL-MG). Orcid: https://orcid.org/0000-0002-9324-7672

E-mail:maraadvsindute@gmail.com

Douglas Franco Bortone: Graduado em Teologia pela Universidade Metodista de São Paulo. Mestrando em Educação pela Universidade Federal de Alfenas (UNIFAL-MG).

Orcid: https://orcid.org/0000-0003-0290-3601

E-mail: douslas.bortone@smail.com 
JuLIANA PereIRA: Licenciada em Química pela Universidade Federal de Alfenas (UNIFAL$M G)$.

Orcid: https://orcid.org/0000-0001-8472-7626

E-mail: juh.alfenas@gmail.com

Priscilla Nayara de Moraes: Licenciada em Química pela Universidade Federal de Alfenas (UNIFAL-MG).

Orcid: https://orcid.org/0000-0003-3435-9612

E-mail: pri.nayaramorais@hotmail.com

AndREIA DA SILVA: Graduanda em Licenciatura em Ciências Sociais pela Universidade Federal de Alfenas (UNIFAL-MG).

Orcid: https://orcid.org/0000-0003-3623-2404

E-mail: andreiasilva3782@smail.com

Este periódico utiliza a licença Creative Commons Attribution 3.0, para periódicos de acesso aberto (Open Archives Iniciative - OAI). 